\title{
How to Reshape the Role of Finance Professional of Big Data Huahong Yan ${ }^{1, a^{*}}$, and Yingying Zhang ${ }^{2, b}$
}

${ }^{1}$ School of Accounting, Capital University of Economics and Business, Beijing 100070, China;

${ }^{2}$ School of Accounting, Capital University of Economics and Business, Beijing 100070, China;

a1159153472@qq.com, bzhangyingying009@126.com,

*The corresponding author

\begin{abstract}
As big data and analysis technology have been deepening the impact on enterprises, the role of finance professional in the enterprise needs to adapt to the new environment. The impact of big data means that accountants and finance professionals are at a crossroads, whether finance professional choose to do nothing and become the victim of new era, or choose to reshape the finance role to respond to the challenges it creates? This paper attempts to help the financial professional to reshape the role by analyzing and demonstrating the new opportunities that big data created for finance professionals and the new challenges they are facing. In addition, in order to meet the needs of the big data, this paper provides some suggestions on how to reshape the role of finance professional of big data.
\end{abstract}

Keywords: Big data; Finance professional; Opportunity; Challenge; Role reshaping

\section{大数据时代下财务人员的角色重塑}

\author{
间华红 ${ }^{1}$, 张莹莹 ${ }^{2}$ \\ (1. 首都经济贸易大学 会计学院, 北京 100070 ; \\ 2. 首都经济贸易大学 会计学院, 北京 100070)
}

摘要: 随着大数据和大数据分析对企业影响的不断深入, 财务人员在企业中的角色也随之发生变化。大数据时代的来 临意味着财务人员正处于当前职业生涯中的“交叉路口”，财务人员是选择固步自封以致最终沦落为时代发展中的牺牲品， 还是选择重新定位主动出击以应对环境变化? 本文分析并阐述了大数据为财务人员创造的新机遇以及财务人员面临的新挑 战, 目的是帮助财务人员进行角色重塑。另外, 为适应大数据时代发展的需求, 本文对财务人员角色重塑应采取的举措提供 了相关的建议。

关键词：大数据；财务人员；机遇；挑战；角色重塑

中图分类号: F830.91 文献标志码: A

引言

目前, 世界许多单纯依靠人类判断力的领域都正在被计算机系统改变甚至取代, 大数据时代已经来临, 在大数据大量性、及时性、多样性、价值性、准确性这 5V (volume、velocity、variety、value、veracity) 特征的驱动下, 能否高效实施数据管理是企业能否发展扩张保持竞争优势的关键, 在企业中只有那些不断 学习新技能和以新思维思考分析的员工才有机会成为企业中的智慧担当, 发挥战略性作用, 正是在这样的 大数据背景下, 财务人员才有了在企业中改变形象并崭露头角的机会。然而, 机遇与挑战共存, 财务人员 对于大数据的管理不仅仅意味着是个机会, 它同时意味着新的挑战, 大数据是把双刃剑, 财务人员只有抓 住机遇并承受住考验才能走在大数据时代的前沿。本文针对如何才能成为与时俱进的 “新” 财务人员阐明 观点, 为帮助财务人员适应大数据时代的发展需求, 对其角色重塑提出了指导性的建议。 


\section{1. 大数据带给财务人员的挑战与机遇}

企业经营模式因大数据和大数据分析技术的影响正在不断发生变化, 财务人员的角色与作用也将随之 发生变化。一些曾经或当前十分受重视的技能或工具会随着大数据的不断深入而逐渐衰落, 同时一些未曾 受到重视或未曾出现的其他技能或将成为新的有力 “武器”。

\section{1 人才的挑战与机遇}

大数据在企业中将会扮演越来越重要的角色，虽然智能工具与技术会代替一部分人力，但充分利用大 数据的过程需要拥有高超的技术能力与分析能力的专业人士进行把控。企业急需集高水平技术分析、专业 素养与创新思维于一身的新型管理人才。这表明, 大数据管理人才的短缺是企业运用大数据技术所必须解 决的问题之一。人才短缺虽是企业的一大难题, 却为财务人员提供了一个绝佳的提升自我的机会。财务人 员应提升应有的技术方面技能, 加强与其他部门的合作与沟通, 同时应改变当前的思维模式, 以全新的视 角去看待企业发展问题，只有做到上述几点，才有可能成为一名为企业所需的更具战略性、更面向未来、 更积极的大数据管理人才, 才可以帮助企业实现提升决策水平、识别管理风险、辅助开发新市场、提升经 营效率、增加利润等目标。

\section{2 数据的大量性与多样性的挑战与机遇}

大数据的大量性与多样性体现出其所涵盖的数据之多、之杂。面对数据价值的测算, 财务人员面临的 挑战有: 如何判断大数据中的有价值信息是哪些? 各种数据都面临减值, 其减值速度有多快等一系列与数 据价值相关的有待解决的问题。谈论数据价值不得不提及数据质量, 因数据质量对数据价值起到了决定性 作用。决策者只有基于高数据质量才能准确判断外部环境并迈出正确的一步。如果数据中掺杂的杂质太多, 一些不相关、不准确的信息会给决策者传递出错误的信号, 从而导致其做出错误的决定。这不仅不会起到 增加企业价值的作用, 甚至会让企业为此付出沉痛的代价。财务人员如何保证数据质量是维护企业数据价 值的第一步，只有在数据质量得以保证的基础上，评估数据价值才有意义。

大数据价值的评估是十分有必要的, 虽然当前暂未开发出准确的估值技术与方法, 但不可否认, 研究 数据估价为财务人员带来了机会, 估价过程要求财务人员在具备专业素养的同时, 更应掌握分析技术的熟 练运用, 站在全局视角对大数据进行深入剖析。财务人员如果能严格把控数据质量, , 使数据符合企业的 质量要求, 保证用于重要决策的数据是来自于可靠来源的并确保所提供的数据质量能够获取内外部利益相 关者们的信任, 那么就能协助企业使得内部数据库更安全可靠且使其更具商业价值, 实现大数据价值的提 升。

未来, 那些能通过可靠的估值方法帮助公司确定大数据资产价值, 通过管理以及质量控制增加数据价 值的财务人员一定会使得他们在企业甚至人才市场上独树一帜。

\section{3 风险管理的挑战与机遇}

随着企业的发展, 企业对于风险管理的重视程度也在不断加深。面对风险, 最重要的是能够及时识别 风险并尽早做出反应将风险进行转移, 识别风险越早越能帮助企业在风险应对上保持主动优势。风险识别 需要一双及时能够在各方各面发现异常信号的 “眼睛”, 那双 “眼睛” 指的就是能做到时刻保持警觉并具 备敏锐洞察力的财务人员, 大数据可以帮助企业囊括更加全面的信息, 他们能够帮助企业进行风险管理与 防范。 


\section{4 业财融合的挑战与机遇}

随着技术的进步，企业可以实现安全的获取、存储以及分析从不同来源获得的多种数据。数据共享对 决策者来讲是个十分有利的工具, 它能丰富企业的数据源, 从而方便企业利用共享平台上的数据进行决策。 虽然财务人员可以通过决定在哪一时点将有效信息与内外部利益相关者分享从而辅助公司最大化数据价 值, 但平台上的其他合作伙伴将数据共享至平台上仍拒绝这一做法。在全新的数据共享领域中, “坚井心 理” 是财务人员实施有效数据管理的劲敌。各部门会因各种原因如机密性、害怕吸引太多注意力或者害怕 在业务的某些方面失去控制而拒绝进行数据共享, 因此他们会保护自有数据。在这种情况下, 财务人员若 想通过数据共享以扩大分析范围, 为决策者提供更多有价值数据是存在困难的。

大数据时代给财务人员创造了一个把数据与公司关键业务相结合的绝佳机会, 财务人员如何将其提供 的决策支撑依据与企业业务相融合十分重要。财务人员如果可以做到及时从数据中提取出有用信息并使得 该数据能够被企业中的其他人员及时获取, 那么这将成为财务人员的一项十分有竞争力的优势。另外财务 人员还可通过数据共享为企业决策提供更多的数据来源与支撑。财务人员能够从企业内外两方提升数据流 动性, 为企业节省时间、金钱、提升效率。他们可以通过决定在哪一时点将有效信息与内外部利益相关者 分享从而辅助公司最大化数据价值, 部门之间及时的数据交换可以提升决策有效性。财务人员可以将该技 能应用到大数据的战略使用中，在企业决策与价值创造中承担起核心与积极的角色。

\section{2. 财务人员的角色重塑}

大数据带来的影响不论是机遇或是威胁都意味着财务人员当前正处于职业生涯中的交叉路口。他们可 以不做任何事情, 看着技术的发展替代他们多年的技能, 同时降低其在企业中的地位, 或者他们可以适应 新的环境并增加他们的影响力、提升他们为企业创造的价值。财务人员应努力将大数据为自己所用以避免 沦为数据时代的牺牲品, 他们可以采取更具战略性的策略协助企业塑造未来, 比如: 训练收集并分析结构 化和非结构化数据、构建模型、提取信息等。

\section{1 提升全面分析预测能力}

财务人员需要结合不同数据来评估企业绩效从而预测风险。对于整体环境分析来讲, 从社交媒体评论 与线上产品的回馈中获取质量信息、环境条件、信用状况以及海外市场政治风险十分重要。另外，非结构 化数据以及从企业系统中难以通过正常渠道所能获取的数据将越来越需要收集和合成。当前的数据收集和 分析来自外部传统财务报告和企业资源规划（ERP）系统的更多信息。环境，社会等数据集越来越多地结 合到一起和详细分析。这种变化在很大程度上是由可持续性和企业社会责任日益增长的重要性驱动的, 在 资产负债表，损益表和现金流量表中发现的财务信息量，与温室气体排放，用水，林业影响，自然资源开 采等非财务信息相比, 其对企业的影响不足为道。另外, 开发量化非结构化数据的方法, 可快速提升非财 务信息收集速度。例如从社交媒体收集的有关消费者态度数据, 关于新出口市场的政治和信用风险的数据 以及关于气候变化和环境风险的数据, 当财务人员能够对收集非财务信息以及非结构化信息十分得心应手 时, 他的价值就能得以体现了。随着市场波动性的增加和操作环境的不确定性意味着财务人员的职能早已 不再局限于提供历史财务报告了。财务人员为了应付增加的波动性、不确定性和风险可以通过大数据和分 析做更多，财务人员应做到从被动转向主动、应将关注点从发生了什么转移至未来会发生什么。 


\section{2 学习技术并加强沟通}

财务人员的分析技能使他们充分具备资质去分析大数据和识别对企业真正有价值的数据集。当前企业 最需要的就是掌握综合分析技术的人才, 因此财务人员进行角色重塑必须学习如何将核心会计技能与数据 科学技能相融合以开辟新的职业发展道路。学习新分析技术为企业创造的价值还可以帮助财务人员弥补因 计算机智能替代当前工作所带来的损失。另外，除技术能力上的加强，与公司的首席信息官以及与 IT 人 员和业务分析师保持密切合作并定期沟通交流, 将有助于财务人员加强对新技术的了解, 提升企业经营效 率, 从而更高效的帮助企业创造价值。如果财务人员与其他部门更密切地合作, 从数据中展现洞察力, 其 在业务中的可见性将大大增加。它将不在被视为是一个服务角色, 而是一个战略合作伙伴, 帮助领导者做 出和验证他们的决定。

\section{3 提升信息提取与信息传递能力}

财务人员将越来越多地要求使用统计和分析技能来 “解读” 数据的意义以及将这些意义传达给决策者。 财务人员不是软件工程师或数据科学家, 但他们可以在将来通过数据科学获取所需信息。大数据时代最重 要的不是你拥有多少的数据, 而是你能从数据中提取并利用多少有效信息以提升价值。因此, 财务人员若 想有效进行大数据管理，必须提升其有效信息提取的能力，这需要财务人员十分了解当前局势，同时能洞 察出数据中隐含的潜在信息, 这种洞察力以及思维运作方式是需要专业素质的培养以及经验的积累共同作 用才能体现的。另外, 财务人员向决策者传递信息的过程, 就是将其从数据中获取的智慧以简要清晰的语 言表述出来。财务人员需要给决策者看到的是从数据中挖掘出的智慧而不是数据, 这并不代表其失去了作 为财务人员 “为数据而生” 的 DNA, 而是指为成为与时俱进的 “新” 财务人员所必须要做的。

\section{3. 研究结论}

大数据时代已经来临, 财务人员面对环境的变化不能再无动于衷下去, 财务人员应意识到大数据对他 们带来的影响是革命性的。只有通过角色重塑以全新的视角去看待财务, 进一步发展他们的核心分析技能 并将其与大数据以及分析技术相结合，才能帮助企业更好的提高运营效率、提升决策水平、管理风险、开 拓新市场。大数据正在带领全世界走向新的开端, 任何行业都在发生翻天覆地的变化, 财务人员只有敢于 抓住机遇并勇于接受挑战才能为自己创造新的机会，在企业中发挥更具战略性，更具前瞻性和更具积极性 的作用。

\section{4. 致谢}

本论文为 2016 年首都经济贸易大学 “促进高校内涵发展定额一校级教改重点项目-论高校国际化会计 人才培养课程设置的优化”的阶段性研究成果。

\section{Acknowledgement}

This paper is the stage research result of the Capital University of Economics and Business "to promote the development of colleges and universities content-school-level teaching reform key project" in 2016.

\section{参考文献:}

[1] 郭万莉. 大数据时代财务人员定位与转型的思考 $[J]$. 财务与会计， 2015，10：10- 12 .

[2] 林楠. 大数据对财务人员的影响探析 [J]. 企业改革与管理，2015，11：99- 100.

[3] 于芳菲. 刍议大数据给财会行业带来的机遇与挑战 $[J]$. 财务与会计， 2015， 5：57.

[4] 许蔚君. 基于战略导向的企业全面预算管理体系构建一一来自广东省电信公司的实例检验 $[\mathrm{J}]$. 财会通讯, 2010, 
27: $12-23$.

[5] 朱朝晖, 宋洁. 基于平衡计分卡的战略导向全面预算流程构建 [J]. 财会通讯, 2009, 20：118- 119.

[6] 钟全汉. 全面预算管理体系的基本框架研究 $[J]$. 财经界, 2010，2：161.

[7] 王亭亭, 刘子旭. 阿里巴巴基于大数据产业链的财务决策 $[\mathrm{J}]$. 财务与会计（理财版），2014， 8：15- 17.

[8] 江文毅. 基于战略导向的企业全面预算管理研究 [D]. 成都：西南财经大学， 2012.

[9] 王俊. 基于商业智能的 A 公司全面预算系统研究[D] . 北京：北京交通大学，2013.

[10] 间华红，毕洁. 大数据环境下全面预算系统的构建 $[\mathrm{J}]$. 财务与会计，2015，8：44-46.

\section{References:}

[1] Guo Wan-li. Study on the orientation and transformation of financial personnel in the big data age [J]. Finance and Accounting, 2015, 10: 10-12.

[2] Lin Nan. Analysis of the impact of large data on financial staff [J]. Enterprise Reform and Management, 2015, 11: 99-100.

[3] Yu Fangfei. On the big data to the accounting industry brought about by the opportunities and challenges [J]. Finance and Accounting, 2015, 5: 57.

[4] $\mathrm{Xu}$ Weijun. Based on the strategy-oriented enterprise comprehensive budget management system construction - from Guangdong Province, the example of telecommunications companies [J]. Finance and Communications, 2010, 27: 12- 23.

[5] Zhu Zhahui, Song Jie. Based on the balanced scorecard strategy-oriented comprehensive budget process construction [J]. Finance and Accounting, 2009, 20: 118- 119.

[6] Zhong Quanhan. Study on the basic framework of comprehensive budget management system [J] .Journal of Finance and Economics, 2010, 2: 161.

[7] Wang Tingting, Liu Zixu. Alibaba based on large data industry chain financial decision [J]. Finance and Accounting (Financial Edition), 2014, 8: 15-17.

[8] Jiang Wenyi. Based on the strategy-oriented enterprise comprehensive budget management research [D]. Chengdu: Southwest University of Finance and Economics, 2012.

[9] Wang Jun. Business-based a company's comprehensive budget system research [D]. Beijing: Beijing Jiaotong University, 2013.

[10] Yan Huahong, Bi Jie. Construction of a comprehensive budget system under large data environment [J]. Finance and Accounting, 2015, 8: 44- 46. 